
PAIN POPULATION: A RANDOMIZED PLACEBO-CONTROLLED TRIAL

\title{
Arvind Kumar.
}

PhD Scholar, M.PT. (Orthopaedics), M.B.A. (Hospital Management), Principal, Shri Usb College Of Physiotherapy, Aburoad, Rajasthan, India.

\section{ABSTRACT}

Background: Low back pain (LBP) is one of the most communal illnesses with a lifetime prevalence estimating to be as high as $84 \%$. Low back pain is found to be one of the foremost causes of health problems in the developed countries. The prevalence of low back pain differs from 5\%-65\%.

Methodology: The study was conducted in an outpatient physical therapy department in Shri. U.S.B. college of Physiotherapy, Abu road, Rajasthan and Lions Physiotherapy Centre, Abu Road, Rajasthan. The participants were 50 patients selected after screening of 84 patients, both male and female sex with primary complaints of nonspecific low back pain. The participants were randomly selected to both group (Group A experimental group \& Group B Control group). Group A received motor control exercises and Group B received detuned SWD \& U.S. respectively. Outcomes of treatment was recorded using NPRS (Numeric pain rating scale ), Lumbar Flexion ROM by Modified Schober Method \& MODI (Modified Oswestry Low Back Pain Disability Index) compared and evaluated during the difference obtained from pre-study to post-study results from MODI, Lumbar Flexion ROM \& NPRS.

Results: Patients allocated to the group A (MCE group) showed significant improvement in functional disability, Lumbar Flexion ROM and pain intensity as compared to the Control group i.e. group B.

Conclusions: While comparing the evaluated report and effects of motor controlled exercise and control group, MCE program was found more effective than control group. This is compared and evaluated during the difference obtained from pre and post studies result from MODI, Lumbar Flexion ROM and NPRS process. Therefore, it appears that motor control exercises has better role in reducing pain and disability in subjects with non-specific LBP.

KEY WORDS- Motor control exercises, Non-specific low back pain, NPRS (Numeric pain rating scale) \& MODI (Modified Oswestry Disability Index).

Address for correspondence: Dr. Arvind kumar, PhD Scholar, M.PT. (Orthopaedics), M.B.A. (Hospital Management), Principal, Shri Usb College Of Physiotherapy, Aburoad, Rajasthan, India.

E-Mail: drarvindmpt@gmail.com

Access this Article online

Quick Response code

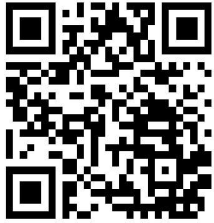

DOI: $10.16965 /$ ijpr.2018.157

Journal Information

International Journal of Physiotherapy and Research

ICV for 2016 ISSN (E) 2321-1822 I ISSN (P) 2321-8975

86.93 https://www.ijmhr.org/ijpr.html DOI-Prefix: https://dx.doi.org/10.16965/ijpr

Article Information

Received: 08 Jun 2018

Peer Review: 08 Jun 2018

Revised: None
Accepted: 06 Jul 2018

Published (O): 11 Aug 2018

Published (P): 11 Aug 2018

\section{INTRODUCTION}

Low back pain is very common complaints which affect the most of the population now a day. If it is present for more than three months, it is said to be chronic Low Back Pain [1].

The type of pain may be sharp or ambiguous or dull, aching, burning, tingling or stabbing. The intensity of pain may be from mild to severe. The onset of pain can possibly be acute, typically and mostly subsides itself within two months. Although it is not life threatening illness but it has a long term impact on medical expenditures for injured workers [2]. 
One of the major causes of low back pain is postural faults. Bad posture can results in pain, discomfort, spasm or disability. White collar jobs has higher incidence of musculo-skeletal disorders [3]. The definition of Low Back Pain is defined as stiffness in the lower back under the costal margin or muscle tension and above the inferior gluteal folds, without or with leg pain [4]. $5-10 \%$ of the adult population affected annually by this [5]. If there is no specific anatomic cause, it is called as non-specific Low Back Pain [6]. It has been confirmed that the $90 \%$ of LBP related to unspecified causes [7]. It has been reported that the weakened abdominal, back, poorly stretched muscles, incorrect posture, obesity, strained muscles from incorrect body mechanics which often results in the NSLBP pain [8].

The lumbar region back pain which lasts for 4 weeks \& more has not been diagnosed as a specific disease or spinal abnormality is termed as NSLBP [9]. Low back pain can be severe enough to affect the daily activities and sometime it may also result in chronic disability. It is most common and frequent problem in a population. The low back pain problem is increasing rapidly. Among the new cases of back pain approximately $80 \%$ leads to chronic back pain. The previous research studies show that 70 to $80 \%$ of population has had the episode of LBP at least once in their lifetime [10]. LBP patients commonly complaint about decreased spinal mobility and disturbances in the loading patterns of the spine [11].

Some specific exercise programs are found to be effective in reducing disability and increasing performance specifically which aim to restore optimal function of trunk muscles [12] The cause of Low Back Pain is multi-fact oral, the exercises also differs to treat patients, ranging from spinal manipulation, advice for postural correction, mobilization, general exercises and dynamic back exercise regime[13]. It has been confirmed that there is a relation between local spinal stabilization muscles and low back pain [14-16].

The spinal stability maintains by the primary muscle group, the core muscles. According to their function and characteristic, it can be divided in to two parts-
The first part of muscles is composed of the deep core muscles or local stabilizing muscles (transversus abdominis, lumbar multifidus, internal oblique and quadratus lumborum) $[17,18]$.The lumbar multifidus muscles have directly attachment to each lumbar vertebral segment. These deep core muscles are responsible for precise motor control and spinal stability $[18,19]$.

The second part is shallow core muscles, also known as global stabilizing muscles, these are the rectus abdominis, external oblique and internal oblique, quadrates lumborum, erector spinae, and hip muscle groups. These muscles provide additional spinal control although they are not directly attached to the spine. The core muscles are also known as "the natural brace" because they helps in segmental stability, protect the spine, and reduces the loading from the lumbar vertebrae and intervertebral discs [18-21].

A motor control exercise improves neuromuscular control, endurance and strength of the muscles which are maintaining spinal and trunk stability [22].

\section{MATERIALS AND METHODS}

Materials: Materials required for the research study are as follows;

-Written informed consent form

-Assessment form

-Modified Oswestry Low Back Pain Disability Questionnaire

-Numerical Pain Rating Scale

-Other miscellaneous equipment/materials (such as Mats, Rulers, and Tapes)

Setting of the study: The study was conducted in Shri U.S.B. college of Physiotherapy, Abu Road, Rajasthan and Lions Physiotherapy Centre, Abu Road, Rajasthan.

Patients: Fifty patients with Non-specific low back pain were collected after screening of 84 patients from Nov. 2016 to April 2018 at Shri USB college of Physiotherapy O.P.D. and Lions Physiotherapy Centre, Abu Road, Rajasthan.

Sampling technique: Sampling technique employed in the following study involves Complete Randomization Sampling. The randomization done by the one investigator who 
was unaware of this study and participants and It was computer-generated and blocked. Sequencing was concealed, sealed in envelop. The patients were assigned to treatment group after opening the next-numbered envelop.

Sample size: The study sample comprises a total of 50 patients with non-specific LBP. From the sample population, a total of 25 patients were subjected to Group A MCE based intervention therapy and the remaining 25 patients to Group B control group.

Duration of the study: 18 months study from Nov. 2016 to April 2018 was conducted

Selection Criteria: The study participants were selected according to inclusion/exclusion criteria as follows;

Inclusion Criteria: The sample populations were included based on -

-The lumbar region of back pain which lasts for 4 weeks $\&$ more has not been diagnosed as a specific disease or spinal abnormality.

-The patients had NSLBP with age from 20 to 65 years for both genders.

-The study populations must be willing to participate in the study.

Exclusion Criteria: The sample populations were excluded based on -

-The LBP less than 4 weeks.

-LBP caused due to medical conditions such as disc herniation, lumbar stenosis, and spinal deformity such as scoliosis, kyphosis, fracture and spondylolisthesis.

-Neurological, systemic illness and infectious diseases such as rheumatologic diseases, tumor, cardiovascular disease.

-Psychiatric/mental deficit

-Patients who had a previous surgical history (within 6 months) were also excluded prior to the baseline assessment.

Intervention: A total of 84 patients were referred to the study and screened for inclusion criteria. 34 patients were not eligible and few refused to participate. Reasons for ineligibility were LBP of less than 4 weeks duration, not expected to continue residing in study area, nerve root compromise, history of back surgery, undergoing any other treatment, not fit to perform physical exercise, pain in other location. 5 participants withdrew from the study .In terms of loss of follow up; main reasons were the participant's lack of time and inability to contact the participants.

After scrutiny out of 84 patients, 50 subjects were divided into both group of 25 each, one group receiving MCE and other one receiving placebo effect. Both groups received 36 hours of treatment over a 12 week period ( 3 sessions per week). After allocating the subjects into specified groups, intervention was provided.

The motor exercise program consists of exercises which were design to improve function of specific muscles of low back region and control of posture and movement. The MCE program was designed on the basis of treatment program of Ferreira et al, Hodges et al \& Costa et al [23-25].MCE exercise program was depend on the motor control impairment, mainly deeper muscles such as transverses abdominis, multifidus, diaphragm \& pelvic floor muscles were assessed and retrained to increase activity of poor controlled muscles. One day workshop organized prior to intervention about how to contract muscles in a proper manner .

There were two stages involved in MCE program.

Stage 1-Includes trained co-ordinate activity of trunk muscles, including independent activation of deeper muscles and reduce over activity of specific superficial muscles in an individualized manner [24]. The exercises program continue until they were able to maintain isolated contractions of muscles for 10 repetitions $X 10$ seconds while maintaining normal respiration [26]. At this stage other exercises like spinal posture correction, breathing control, L/L \& trunk exercises also performed.

Stage 2-Implement precision of desired coordination and train these skills in static tasks and incorporate them into dynamic tasks and functional positions.

It also involved exercises program towards more functional activities and static to dynamic tasks. Arvind Kumar. ROLE OF MOTOR CONTROL EXERCISES IN NON-SPECIFIC LOW BACK PAIN POPULATION: A RANDOMIZED PLACEBO-CONTROLLED TRIAL.The placebo intervention consisted of $20 \mathrm{~min}$. of detuned SWD and $5 \mathrm{~min}$. U.S. for 36 weeks over a 12 week period ( 3 sessions/week)

Outcome measures: Outcome measures of the 
ing the patient's baseline functions at the beginning of intervention period, for evaluating the intervention's/treatment's end outcome. The outcome measures used in the following studies were: Modified Oswestry Disability Index (MODI), Numeric Pain Rating Scale (NPRS) and Lumbar Flexion ROM by Modified Schober Method.

Modified Oswestry Disability Index: The Modified Oswestry Disability Index was performed with sets of a questionnaire which were designed in order to give the therapist with the prior information about the back pain and its impact in affecting the patient's daily routine and how it affects the patient from managing certain activities in their daily life. The patient must be answering each questionnaire by marking the box which represents or describes the condition you are experiencing or apt for your current condition. At times patients may witness two options to be suitable to mark for the particular questionnaire. Under such instance, the patient must be instructed prior, in order to mark the option which seems to be closely related to his condition [27].

Scoring Criteria: The MODI is made up of 10 questions. Each question is scored from 0-5 (minimum to maximum). If the first statement is marked, the section score will be 0 or if the last statement is marked, the section score will be 5 . The point total from each section is summed and the then divided by the total number of questions answered and then multiplied by 100 to create a percentage disability. The scores range from $0-100 \%$ with lower scores meaningless disability.

Typically, we can just add up the score from each section and double it to get the final percentage score.

MODI= (Sum of items scored/Sum of sections answered) $\times 100$

Oswestry scores may be classified as:

-Minimal disability (0-20) \%

-Moderate disability (20-40) \%

-Severe disability (40-60) \%

-Crippled disability (60-80) \%

-Confined to bed (80-100) \%

Numeric Pain Rating Scale: The Numeric Pain
Rating Scale which is abbreviated as NPRS serves as an effective uni-dimensional measurement for estimating the pain intensity for the patients, especially for those who are suffering from chronic medical conditions such as Non-specific LBP in this case. NPRS is known as the numerically segmented version representing VAS. The study implemented 11-point numeric scale ranging from 0 to 10 . The standardized representation of the pain scale of NPRS comprises of a numeric version in a horizontal line/bar in segmented format (greater the value of the number, greater is the intensity of the pain experienced by the patient). The respondent/ patient must select the number based upon the intensity of the LBP experienced.

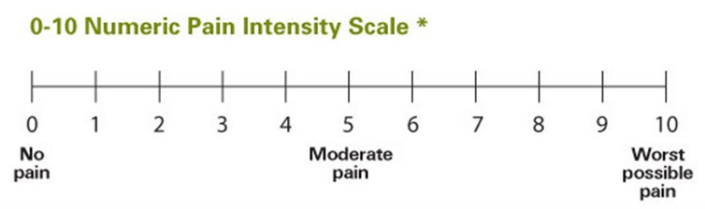

Lumbar Flexion ROM by Modified Schober Method: First mark two landmarks which are a point bisecting a line from the two PSIS (Posterior Superior Iliac Spine) called base line and a second mark $15 \mathrm{~cm}$ above the base line point. The inter tester reliability of this test was excellent with $r$ value of +1.0 . Pearson's reliability coefficients were calculated on paired results of two tester [28].

Data analysis: Statistical Package for social science (SPSS) program version 17 was used for all statistical measures. Descriptive analysis was done to determine the mean and standard deviation of age, BMI and other demographic data for both the group $A$ and group $B$. This analysis was done by using paired and unpaired test were performed to detect level of significance within and between groups respectively.

\section{RESULTS}

Total 50 patients were included in the data analysis. The patients have divided into two groups; group A MCE group consisted of 25 patients (17 males and 8 females) receiving motor control exercises and the group B control group consisted of 25 patients (13 males and 12 females) receiving placebo treatment. The independent $t$ test revealed that there were 
significant improvement in experimental group compare to controlled group. The mean values were $35.44 \pm 8.39$ (Pre MODI) and $17.52 \pm 4.40$ (Post MODI) (Table 7), the mean values for pre NPRS was $4.60 \pm 1.15$ where as post NPRS was $1.44 \pm 1.08$ (Table 9), the ROM also shows significant improvement with the value Pre ROM 5.53 \pm 0.64 and Post ROM-6.31 \pm 0.71 (Table 11) in the experimental group.

Data were collected from both two groups group A and group B, statistically analyzed and compared with measurable variables obtained pre and post treatment; using paired and unpaired $t$ test to find out level of significance within and between groups respectively.

Table 1: Illustrates the mean and standard deviation values of age group.

\section{Descriptive Statistics}

\begin{tabular}{|c|c|c|c|c|c|}
\hline \multicolumn{7}{|c|}{ Descriptive Statistics } \\
\hline & N & Minimum & Maximum & Mean & $\begin{array}{c}\text { Std. } \\
\text { Deviation }\end{array}$ \\
\hline MA1 & 25 & 35 & 63 & 46.72 & 7.99229 \\
\hline $\begin{array}{c}\text { Valid } \\
\text { N(listwise) }\end{array}$ & 25 & & & & \\
\hline
\end{tabular}

The mean and standard deviation values of age group for the experimental group, receiving MCE treatment. The mean age was $46.72 \pm 7.99$ years.

Table 2: Illustrates the mean and standard deviation values of age group for the placebo group.

\begin{tabular}{|c|c|c|c|c|c|}
\hline \multicolumn{5}{|c|}{ Descriptive Statistics } \\
\hline & N & Minimum & Maximum & Mean & $\begin{array}{c}\text { Std. } \\
\text { Deviation }\end{array}$ \\
\hline MA2 & 25 & 24 & 64 & 45.48 & 8.78028 \\
\hline $\begin{array}{c}\text { Valid N } \\
\text { (listwise) }\end{array}$ & 25 & & & & \\
\hline
\end{tabular}

The mean and standard deviation values of age group for the placebo control group, receiving placebo treatment. The mean age was $45.48 \pm$ 8.78 years.

Table 3: Illustrates the mean and standard deviation values of BMI for the experimental group.

\section{Descriptive Statistics}

\begin{tabular}{|c|c|c|c|c|c|}
\hline \multicolumn{7}{|c|}{ Descriptive Statistics } \\
\hline & N & Minimum & Maximum & Mean & $\begin{array}{c}\text { Std. } \\
\text { Deviation }\end{array}$ \\
\hline BMI1 & 25 & 20.63 & 31.17 & 25.5124 & 2.31632 \\
\hline $\begin{array}{c}\text { Valid N } \\
\text { (listwise) }\end{array}$ & 25 & & & & \\
\hline
\end{tabular}

The mean and standard deviation values of BMI for the experimental group, receiving MCE treatment. The mean BMI was $25.51 \pm 2.31$.
Table 4: Illustrates the mean and standard deviation values of $\mathrm{BMI}$ for the placebo control group, receiving placebo training.

\section{Descriptive Statistics}

Table 4: Illustrates the mean and standard deviation values of BMI for the placebo control group, receiving placebo training.

\begin{tabular}{|c|c|c|c|c|c|}
\hline \multicolumn{7}{|c|}{ Descriptive Statistics } \\
\hline & N & Minimum & Maximum & Mean & $\begin{array}{c}\text { Std. } \\
\text { Deviation }\end{array}$ \\
\hline BMI2 & 25 & 19.36 & 34.6 & 25.1808 & 3.15208 \\
\hline $\begin{array}{c}\text { Valid N } \\
\text { (list wise) }\end{array}$ & 25 & & & & \\
\hline
\end{tabular}

The mean and standard deviation values of BMI for the placebo control group, receiving placebo treatment. The mean BMI was $25.18 \pm 3.15$.

Table 5: Illustrates the mean and standard deviation values of duration of pain for the experimental group.

\section{Descriptive Statistics}

\begin{tabular}{|c|c|c|c|c|c|}
\hline \multicolumn{5}{|c|}{ Descriptive Statistics } \\
\hline & N & Minimum & Maximum & Mean & Std. Deviation \\
\hline DOP1 & 25 & 4 & 16 & 8.96 & 3.07517 \\
\hline $\begin{array}{c}\text { Valid N } \\
\text { (list wise) }\end{array}$ & 25 & & & & \\
\hline
\end{tabular}

The mean and standard deviation values of duration of pain for the experimental group, receiving MCE treatment. The mean duration of pain was $8.96 \pm 3.07$.

Table 6: Illustrates the mean and standard deviation values of duration of pain for the placebo control group. Descriptive Statistics

\begin{tabular}{|c|c|c|c|c|c|}
\hline \multicolumn{7}{|c|}{ Descriptive Statistics } \\
\hline & $\mathbf{N}$ & Minimum & Maximum & Mean & $\begin{array}{c}\text { Std. } \\
\text { Deviation }\end{array}$ \\
\hline DOP2 & 25 & 4 & 16 & 8.64 & 3.36502 \\
\hline $\begin{array}{c}\text { Valid N } \\
\text { (list wise) }\end{array}$ & 25 & & & & \\
\hline
\end{tabular}

The mean and standard deviation values of duration of pain for the placebo control group, receiving placebo treatment was $8.64 \pm 3.36$.

\section{T TEST}

Table 7: Illustrates the within group analysis of mean and standard deviation values of PRE \& POST MODI score.

\section{One-Sample Statistics}

\begin{tabular}{|c|c|c|c|c|}
\hline \multicolumn{5}{|c|}{ One-Sample Statistics } \\
\hline & $\mathbf{N}$ & Mean & $\begin{array}{c}\text { Std. } \\
\text { Deviation }\end{array}$ & $\begin{array}{c}\text { Std. Error } \\
\text { Mean }\end{array}$ \\
\hline PREMODI1 & 25 & 35.44 & 8.39682 & 1.67936 \\
\hline POSTMODI1 & 25 & 17.52 & 4.40757 & 0.88151 \\
\hline
\end{tabular}


One-Sample Test

\begin{tabular}{|c|c|c|c|c|c|c|}
\hline \multicolumn{7}{|c|}{ One-Sample Test } \\
\hline & \multicolumn{6}{|c|}{ Test Value $=0$} \\
\hline & & & & & $\begin{array}{r}95 \% \mathrm{C} \\
\text { Inter } \\
\text { Diff }\end{array}$ & $\begin{array}{l}\text { fidence } \\
\text { of the } \\
\text { ence }\end{array}$ \\
\hline & $\begin{array}{llllll}T & \end{array}$ & df & $\begin{array}{l}\text { Sig. (2- } \\
\text { tailed) }\end{array}$ & $\begin{array}{c}\text { Mean } \\
\text { Difference }\end{array}$ & Lower & Upper \\
\hline PREMODI1 & 21.103 & 24 & 0 & 35.44 & 31.974 & 38.906 \\
\hline POSTMODI1 & 19.875 & 24 & 0 & 17.52 & 15.7006 & 19.3394 \\
\hline
\end{tabular}

The within group analysis of mean and standard deviation values of PRE \& POST MODI Scores for the experimental group receiving MCE treatment using t- test. The PRE MODI score was $35.44 \pm 8.39$ where as POST MODI score was $17.52 \pm 4.40$, stating improvement in patient condition as there was significant reduction in scores with $95 \%$ of confidence interval.

Table 8: illustrates the within group analysis of mean and standard deviation values of PRE \& POST MODI Scores.

\section{One-Sample Statistics}

\begin{tabular}{|c|c|c|c|c|}
\hline \multicolumn{5}{|c|}{ One-Sample Statistics } \\
\hline & N & Mean & $\begin{array}{c}\text { Std. } \\
\text { Deviation }\end{array}$ & $\begin{array}{c}\text { Std. Error } \\
\text { Mean }\end{array}$ \\
\hline NPRS1 & 25 & 4.6 & 1.1547 & 0.23094 \\
\hline POSTNPRS1 & 25 & 1.44 & 1.08321 & 0.21664 \\
\hline
\end{tabular}

One-Sample Test

\begin{tabular}{|c|c|c|c|c|c|c|}
\hline \multicolumn{7}{|c|}{ One-Sample Test } \\
\hline & \multicolumn{6}{|c|}{ Test Value $=0$} \\
\hline & & & & & $\begin{array}{r}95 \% \text { Co } \\
\text { Interv } \\
\text { Diff }\end{array}$ & $\begin{array}{l}\text { fidence } \\
\text { of the } \\
\text { ence }\end{array}$ \\
\hline & $\mathbf{T}$ & df & $\begin{array}{l}\text { Sig. (2- } \\
\text { tailed) }\end{array}$ & $\begin{array}{c}\text { Mean } \\
\text { Difference }\end{array}$ & Lower & Upper \\
\hline NPRS1 & 19.919 & 24 & 0 & 4.6 & 4.1234 & 5.0766 \\
\hline POSTNPRS1 & 6.647 & 24 & 0 & 1.44 & 0.9929 & 1.8871 \\
\hline
\end{tabular}

The within group analysis of mean and standard deviation values of PRE \& POST MODI Scores for the control group receiving placebo treatment using t- test. The PRE MODI score was 35.28 7.82 where as POST MODI score was $29.92 \pm 8.51$, stating reduction in scores but not as much as shown in experimental group.

Table 9: Illustrates the within group analysis of mean and standard deviation values of PRE \& POST NPRS Scores.

\section{One-Sample Statistics}

\begin{tabular}{|c|c|c|c|c|}
\hline \multicolumn{5}{|c|}{ One-Sample Statistics } \\
\hline & $\mathbf{N}$ & Mean & $\begin{array}{c}\text { Std. } \\
\text { Deviation }\end{array}$ & $\begin{array}{c}\text { Std. Error } \\
\text { Mean }\end{array}$ \\
\hline NPRS2 & 25 & 5.44 & 1.26095 & 0.25219 \\
\hline POSTNPRS2 & 25 & 3.92 & 1.41185 & 0.28237 \\
\hline
\end{tabular}

\section{One-Sample Test}

\begin{tabular}{|c|c|c|c|c|c|c|}
\hline \multicolumn{7}{|c|}{ One-Sample Test } \\
\hline & \multicolumn{6}{|c|}{ Test Value $=0$} \\
\hline & & & & & $\begin{array}{r}95 \% \mathrm{Cc} \\
\text { Interv } \\
\text { Diff }\end{array}$ & $\begin{array}{l}\text { fidence } \\
\text { of the } \\
\text { ence }\end{array}$ \\
\hline & T & df & $\begin{array}{l}\text { Sig. (2- } \\
\text { tailed) }\end{array}$ & $\begin{array}{c}\text { Mean } \\
\text { Difference }\end{array}$ & Lower & Upper \\
\hline NPRS2 & 21.571 & 24 & 0 & 5.44 & 4.9195 & 5.9605 \\
\hline POSTNPRS2 & 13.882 & 24 & 0 & 3.92 & 3.3372 & 4.5028 \\
\hline
\end{tabular}

The within group analysis of mean and standard deviation values of PRE \& POST NPRS Scores for the experimental group receiving MCE treatment using t- test. The PRE NPRS score was $4.60 \pm 1.15$ where as POST NPRS score was $1.44 \pm 1.08$, stating improvement in patient condition as there was significant reduction in scores with $95 \%$ of confidence interval.

Table 10: Illustrates the within group analysis of mean and standard deviation values of PRE \& POST NPRS Scores.

\section{One-Sample Statistics}

\begin{tabular}{|c|c|c|c|c|}
\hline \multicolumn{5}{|c|}{ One-Sample Statistics } \\
\hline & N & Mean & $\begin{array}{c}\text { Std. } \\
\text { Deviation }\end{array}$ & $\begin{array}{c}\text { Std. Error } \\
\text { Mean }\end{array}$ \\
\hline PREROM1 & 25 & 5.536 & 0.648 & 0.1296 \\
\hline POSTROM1 & 25 & 6.312 & 0.71199 & 0.1424 \\
\hline
\end{tabular}

\section{One-Sample Test}

\begin{tabular}{|c|c|c|c|c|c|c|}
\hline \multicolumn{7}{|c|}{ One-Sample Test } \\
\hline & \multicolumn{7}{|c|}{ Test Value = 0 } & \multicolumn{2}{|c|}{$\begin{array}{c}\text { 95\% Confidence } \\
\text { Interval of the } \\
\text { Difference }\end{array}$} \\
\hline & \multicolumn{7}{|c|}{} & \multicolumn{2}{|c|}{$\begin{array}{c}\text { Mean } \\
\text { Lig. (2- } \\
\text { tailed) }\end{array}$} & $\begin{array}{c}\text { Difference } \\
\text { Lower }\end{array}$ & Upper \\
\hline NPRS2 & 21.571 & 24 & 0 & 5.44 & 4.9195 & 5.9605 \\
\hline POSTNPRS2 & 13.882 & 24 & 0 & 3.92 & 3.3372 & 4.5028 \\
\hline
\end{tabular}

The within group analysis of mean and standard deviation values of PRE \& POST NPRS Scores for the control group receiving placebo treatment using t- test. The PRE NPRS score was $5.44 \pm 1.26$ where as POST NPRS score was $3.9 \pm 1.41$, stating reduction in scores but not as much as shown in experimental group.

Table 11: Illustrates the within group analysis of mean and standard deviation values of PRE \& POST ROM Scores.

\section{One-Sample Statistics}

\begin{tabular}{|c|c|c|c|c|}
\hline \multicolumn{5}{|c|}{ One-Sample Statistics } \\
\hline & $\mathbf{N}$ & Mean & $\begin{array}{c}\text { Std. } \\
\text { Deviation }\end{array}$ & $\begin{array}{c}\text { Std. Error } \\
\text { Mean }\end{array}$ \\
\hline PREROM1 & 25 & 5.536 & 0.648 & 0.1296 \\
\hline POSTROM1 & 25 & 6.312 & 0.71199 & 0.1424 \\
\hline
\end{tabular}




\begin{tabular}{|c|c|c|c|c|c|c|}
\hline \multicolumn{7}{|c|}{ One-Sample Test } \\
\hline & \multicolumn{8}{|c|}{ Test Value = 0 } & $\begin{array}{c}\text { 95\% Confidence } \\
\text { Interval of the } \\
\text { Difference }\end{array}$ \\
\hline & T & df & $\begin{array}{c}\text { Sig. (2- } \\
\text { tailed) }\end{array}$ & $\begin{array}{c}\text { Mean } \\
\text { Difference }\end{array}$ & Lower & Upper \\
\hline PREROM1 & 42.716 & 24 & 0 & 5.536 & 5.2685 & 5.8035 \\
\hline POSTROM1 & 44.326 & 24 & 0 & 6.312 & 6.0181 & 6.6059 \\
\hline
\end{tabular}

The within group analysis of mean and standard deviation values of PRE \& POST ROM Scores for the experimental group receiving MCE treatment using t- test. The PRE ROM score was $5.53 \pm 0.64$ where as POST ROM score was $6.31 \pm 0.71$, stating improvement in patient condition as there was significant increase in scores.

Table 12: Illustrates the within group analysis of mean and standard deviation values of PRE \& POST ROM Scores.

\section{One-Sample Statistics}

\begin{tabular}{|c|c|c|c|c|}
\hline \multicolumn{5}{|c|}{ One-Sample Statistics } \\
\hline & $\mathbf{N}$ & Mean & $\begin{array}{c}\text { Std. } \\
\text { Deviation }\end{array}$ & $\begin{array}{c}\text { Std. Error } \\
\text { Mean }\end{array}$ \\
\hline PREROM2 & 25 & 5.292 & 0.62844 & 0.12569 \\
\hline POSTROM2 & 25 & 5.46 & 0.48391 & 0.09678 \\
\hline
\end{tabular}

One-Sample Test

\begin{tabular}{|c|c|c|c|c|c|c|}
\hline \multicolumn{7}{|c|}{ One-Sample Test } \\
\hline & \multicolumn{6}{|c|}{ Test Value $=0$} \\
\hline & & & & & $\begin{array}{r}95 \% \mathrm{Co} \\
\text { Interv } \\
\text { Diffe }\end{array}$ & $\begin{array}{l}\text { fidence } \\
\text { lof the } \\
\text { ence }\end{array}$ \\
\hline & $T$ & df & $\begin{array}{l}\text { Sig. (2- } \\
\text { tailed) }\end{array}$ & $\begin{array}{c}\text { Mean } \\
\text { Difference }\end{array}$ & Lower & Upper \\
\hline PREROM2 & 42.104 & 24 & 0 & 5.292 & 5.0326 & 5.5514 \\
\hline POSTROM2 & 56.416 & 24 & 0 & 5.46 & 5.2603 & 5.6597 \\
\hline
\end{tabular}

The within group analysis of mean and standard deviation values of PRE \& POST ROM Scores for the control group receiving placebo treatment using t- test. The PRE ROM score was $5.29 \pm 0.62$ where as POST ROM score was $5.46 \pm 0.48$, stating there was no significant increase in scores.

Table 13: Illustrates the within group analysis of mean and standard deviation values of BMI Scores.

\section{One-Sample Statistics}

\begin{tabular}{|c|c|c|c|c|}
\hline \multicolumn{5}{|c|}{ One-Sample Statistics } \\
\hline & N & Mean & $\begin{array}{c}\text { Std. } \\
\text { Deviation }\end{array}$ & $\begin{array}{c}\text { Std. Error } \\
\text { Mean }\end{array}$ \\
\hline BM11 & 25 & 25.5124 & 2.31632 & 0.46326 \\
\hline BMI2 & 25 & 25.1808 & 3.15208 & 0.63042 \\
\hline
\end{tabular}

\section{One-Sample Test}

\begin{tabular}{|c|c|c|c|c|c|c|}
\hline \multicolumn{7}{|c|}{ One-Sample Test } \\
\hline & \multicolumn{7}{|c|}{ Test Value = 0 } & $\begin{array}{c}\text { 95\% Confidence } \\
\text { Interval of the } \\
\text { Difference }\end{array}$ \\
\hline & \multicolumn{8}{|c|}{} & $\begin{array}{c}\text { Mean } \\
\text { Sig. (2- } \\
\text { tailed) }\end{array}$ & Difference & Lower & Upper \\
\hline & T & df & 25.5563 & 26.4685 \\
\hline BM11 & 55.071 & 24 & 0 & 25.5124 & 24.579 & 26.4819 \\
\hline BMI2 & 39.943 & 24 & 0 & 25.1808 & 23.8797 \\
\hline
\end{tabular}

The within group analysis of mean and standard deviation values of BMI Scores for the experimental group receiving MCE treatment and control group using t- test. The BMI score for experimental group was $25.51 \pm 2.31$ where as BMI score for control group was $25.18 \pm 3.15$, stating that BMI in both groups was near about the same.

Table 14: Illustrates the within group analysis of mean and standard deviation values of Duration of pain.

\section{One-Sample Statistics}

\begin{tabular}{|c|c|c|c|c|}
\hline \multicolumn{5}{|c|}{ One-Sample Statistics } \\
\hline & $\mathbf{N}$ & Mean & $\begin{array}{c}\text { Std. } \\
\text { Deviation }\end{array}$ & $\begin{array}{c}\text { Std. Error } \\
\text { Mean }\end{array}$ \\
\hline DOP1 & 25 & 8.96 & 3.07517 & 0.61503 \\
\hline DOP2 & 25 & 8.64 & 3.36502 & 0.673 \\
\hline
\end{tabular}

\section{One-Sample Test}

\begin{tabular}{|c|c|c|c|c|c|c|}
\hline \multicolumn{7}{|c|}{ One-Sample Test } \\
\hline & \multicolumn{8}{|c|}{ Test Value = 0 } & \multicolumn{2}{c|}{$\begin{array}{c}\text { 95\% Confidence } \\
\text { Interval of the } \\
\text { Difference }\end{array}$} \\
\hline & T & df & $\begin{array}{c}\text { Sig. (2- } \\
\text { tailed) }\end{array}$ & $\begin{array}{c}\text { Mean } \\
\text { Difference }\end{array}$ & Lower & Upper \\
\hline DOP1 & 14.568 & 24 & 0 & 8.96 & 7.6906 & 10.2294 \\
\hline DOP2 & 12.838 & 24 & 0 & 8.64 & 7.251 & 10.029 \\
\hline
\end{tabular}

The within group analysis of mean and standard deviation values of Duration of pain in experimental group \& control group using t- test. The duration of pain in experimental group was $8.9 \pm 3.07$ where as control group score was $8.6 \pm 3.36$, stating the baseline scores were similar in both the groups.

\section{DISCUSSION}

The aims of this study were to evaluate the effects of motor control exercises in improving pain, disability and ROM. This randomized controlled trial established that MCE had better effect when compared to the placebo control group in reducing pain and improving the 
functional outcomes, reducing the disability due to pain in patients with non specific low back pain.

During study the optimal implementation of both treatment programs was ensured. The interventions included supervised individualized sessions.

Prior studies mentioned the evidence of a beneficial but small effect of MCE on global impression of recovery, activity and activity limitation.

The improvements seen in activity, activity limitation and global impression of recovery, can be explained as training can change trunk muscle behavior during functional task and subjects can be taught to control their trunk muscles.

As exact biological basis for efficacy is still unclear, there are other mechanism including reduced load and improved quality of movement, as a result of improved co-ordination of trunk musculature.

Even patients having baseline motor control deficits including decreased activation of transverses abdominis and decreased proprioception would have benefitted more from a placebo effect or through machines in patients having kinesiophobia.

There are earlier works and studies supporting our findings that motor control exercises produced a small reduction in risk for persistent pain at 12 months.

Another study done by Schulz K.F. et al in 1995 suggests that patients having impairment of deep trunk musculature, experience more impairment of deep trunk musculature, experience more recurrent low back pain episodes. There is no placebo exercise which is credible and inert but reduction in pain, disability and ROM may be attributed to the psychological effect of control group (untuned U.S. and SWD).

Limitations of the study A small sample size and with less number of outcomes. Lumbar flexion ROM taping measurement technique may affect the result, would like to use inclinometer.

\section{CONCLUSION}

Motor control exercise technique is a statisti- cally significant technique, which is helpful in the improvement of functional disability, severity of pain and lumbar flexion range of motion but reduction in pain, disability and increased ROM may be attributed to the psychological effect of control group (untuned U.S. and SWD).

\section{ABBREVIATIONS}

NPRS- Numeric Pain Rating Scale

MCE-Motor Control Exercise

NSLBP-Non-Specific Low Back Pain

LBP-Low Back Pain

VAS-Visual Analogue Scale

MODI-Modified Oswestry Disability Index

ROM- Range of Motion

\section{ACKNOWLEDGEMENTS}

The authors acknowledge the management of Shri USB Group of College, All faculty members of Shri USB college of Physiotherapy for providing resources that contributed to this study and also the last but not least the patients for their supportive nature and cooperation.

\section{Conflicts of interest: None}

\section{REFERENCES}

[1]. Haldeman S, Dagenais S. A supermarket approach to the evidence-informed management of chronic low back pain. Spine J. 2008;8(1):1-7.

[2]. Leboeuf-yde, C, kyvik,k.At what age does low back pain become a common problem? A study of 29434 individuals aged 12-41 years .spine 1998;23:228234.

[3]. Karahan A, Bayraktar N. Determination of the usage of body mechanics in clinical setting and the occurrence of low back pain in nurses. International Journal of Nursing Studies 2004;41:67-75.

[4]. Koes, B. W., Van Tulder, M. W., \& Thomas, S. Diagnosis and treatment of low back pain. BMJ: British Medical Journal, 2006;332(7555):1430.

[5]. Bronfort G, Goldsmith C, Nelson C, boline P and Anderson A. Trunk exercise combined with spinal manipulative or NSAID therapy for chronic low back pain: a randomized, observer -blinded clinical trial. Journal of Manipulative Physical therapy. 1996;19:570-582.

[6]. Vuori IM. Dose-response of physical activity and low back pain, osteoarthritis, and osteoporosis. Medicine and science in sports and exercise. 2001;33:551-586.

[7]. Koes, B. W., Van Tulder, M. W., \& Thomas, S. Diagnosis and treatment of low back pain. BMJ: British Medical Journal, 2006;332(7555):1430. 
[8]. Tekur, P., Singphow, C., Nagendra, H. R., \& Raghuram, $\mathrm{N}$. Effect of short-term intensive yoga program on pain, functional disability and spinal flexibility in chronic low back pain: a randomized control study. The journal of alternative and complementary medi ine, 2008;14(6), 637-644.

[9]. Chou, R., Qaseem, A., Snow, V., Casey, D., Cross, J. T., Shekelle, P., \& Owens, D. K. Diagnosis and Treatment of Low Back Pain: A Joint Clinical Practice Guideline from the American College of Physicians and the American Pain Society Diagnosis and Treatment of Low Back Pain. Annals of internal medicine, 2007;147(7):478-491.

[10]. S.Brent Brotzman, Kevin E. Wilk. Clinical orthopaedics rehabilitation $2^{\text {nd }}$ edition mosby, 2003 .

[11]. Shum,L.,Bonnie Y.,Raymond Y. The immediate Effect of Posteroanterior Mobilization on Reducing Back Pain and the Stiffness of the Lumbar Spine. ACRM 2013;94:673-9.

[12]. Mannion AF, Muntener M, Taimela S and Dvork H. A randomized clinical trial of three active therapies for chronic low back pain. Spine 1999;24:24352438.

[13]. Liddle SD, David Baxter G, Gracey JH: Physiotherapist 'use of advice and exercise for the management of chronic low back pain: a national survey. Man Ther 2009;14:189-196.

[14]. Hodges PW, Richardson CA: Inefficient muscular stabilization of the lumbar spine associated with low back pain. A motor control evaluation of transversus abdominis. Spine (Phila Pa 1976) 1996;21:2640-2650.

[15]. Hodges PW, Richardson CA: Altered trunk muscle recruitment in people with low back pain with upper limb movement at different speeds. Arch Phys Med Rehabil 1999;80:1005-1012.

[16]. Richardson C, Jull G, Hodges P, Hides J: Therapeutic Exercise for Spinal Segmental Stabilization: In Lower Back Pain. Edinburgh: Churchill Livingstone;1999.

[17].Peng $H$ Y,Lin TB: spinal pelvic-urethra reflex potentiation.Biomedicine,2012;2:64-67.

[18]. Huang JT,Chen HY,Hong CZ.et al:Lumbar facet injection for the treatment of chronic piriformis muofascial pain syndrome:52 case studies .Patient prefer Adherence.2014;8:1105-1111.

[19]. Aluko A, DeSouza L, Peacock J: The effect of core stability exercises on variations in acceleration of trunk movement, pain, and disability during an episode of acute nonspecific low back pain: a pilot clinical trial. J Manipulative Physiol Ther, 2013;36: 497-504, e1-e3.
[20]. Ekstrom RA, Donatelli RA, Carp KC: Electromyographic analysis of core trunk, hip, and thigh muscles during 9 rehabilitation exercises. J Orthop Sports Phys Ther, 2007;37:754-762.

[21]. Ezechieli M, Siebert $\mathrm{CH}$, Ettinger $\mathrm{M}$, et al.: Muscle strength of the lumbar spine in different sports. Technol Health Care, 2013;21:379-386.

[22]. Standaert CJ, Weinstein SM, Rumpeltes J. Evidenceinformed management of chronic low back pain with lumbar stabilization exercises. Spine J 2008;8:11420.

[23]. Ferreira ML,Ferreira PH,Latimer, I, et al. Comparision of general exercise, motor control exercise and spinal manipulative therapy for chronic low back pain:A randomized trial.Pain.2007;131:31-37.

[24]. Hodges PW, Ferreira PH, Ferreira M. Lumbar spine: treatment of instability and disorders of movement control. In: Magee DJ, Zachazewski JE, Quillen WS, eds. Pathology and intervention in Musculoskeletal Rehabilitation. Amsterdam, the Netherlands: Elsevier Science BV;2007:389-425.

[25]. Costa LOP,Maher CG,Latimer J,et al.Motor control exercises for chronic low back pain:A randomized placebo controlled trial.Phys Ther.2009;89:12751286.

[26]. Richardson CA, Jull GA, Hodges PW. Therapeutic Exercise for Spinal Segmental Stabilization in Low Back Pain. Edinburgh, Scotland: Churchill Livingstone; 1999.

[27]. Fair bank J,Roland M.The Roland -Morris Disability Questionnaire and the Oswestry Disability Questionnaire.Spine.2000;25:3115-24.

[28]. Fitzqerald , G.K. et. al .:Objective assessment with establishment of normal values for lumbar spine for range of motion,Physical Therapy 1983;63:1776.

How to cite this article:
Arvind Kumar. ROLE OF MOTOR CONTROL EXERCISES IN NON-SPECIFIC
LOW BACK PAIN POPULATION: A RANDOMIZED PLACEBO-CONTROLLED
TRIAL. Int J Physiother Res 2018;6(4):2823-2831. DOI: 10.16965/
ijpr.2018.157 